\title{
LUDWIG TIECK: MEANDROS GÓTICOS
}

Karin Volobuef

Universidade Estadual Paulista - campus Araraquara

\section{Resumo}

Ludwig Tieck (1773-1853) foi um dos pioneiros do Romantismo alemão ao lado de figuras como Novalis, Wackenroder, os irmãos August e Friedrich Schlegel, Schleiermacher, Schelling. Grande admirador de Shakespeare e Calderón de la Barca, Tieck concebia a literatura como terreno supranacional e como área de convergência de diferentes tradições e perspectivas. Com isso, absorveu inúmeros elementos da cultura popular (contos de fadas, lendas, superstições) e os fundiu a vertentes de sua época, entre as quais a da narrativa gótica e de horror, em voga desde a segunda metade do século XVIII. Em Tieck, o macabro tornase expressão de questionamentos sobre a relação entre sujeito e mundo e sobre a própria noção (inspirada no senso comum) de que existiria uma realidade única e independente do ponto de vista daquele que a observa ou descreve. Tieck formulou esteticamente indagações que ecoaram pelo Romantismo alemão, expressando anseios e inquietações indissociáveis de sua produção poético-literária.

Palavras-chave: Tieck, Romantismo, gótico, maravilhoso.

\begin{tabular}{|l|l|l|l|l|}
\hline Ilha do Desterro & Florianópolis & $n^{\circ} 62$ & p. 153-172 & jan/jun 2012 \\
\hline
\end{tabular}




\title{
LUDWIG TIECK: GOTHIC TWISTINGS
}

\begin{abstract}
Ludwig Tieck (1773-1853) was a pioneer of German Romanticism alongside figures such as Novalis, Wackenroder, brothers August and Friedrich Schlegel, Schleiermacher, Schelling. A great admirer of Shakespeare and Calderón de la Barca, Tieck envisioned literature as a supranational terrain and an area of convergence of different traditions and perspectives. Thus he absorbed numerous elements from popular culture (fairy tales, legends, superstitions) and merged with the trends of his time, among which the mid eighteenth-century gothic and horror narrative. In Tieck the macabre becomes an expression of questions about the relationship between the subject and on the very notion (based on common sense) that there would be a single reality and independent from the point of view of who observes or describes. Tieck aesthetically formulated questions that echoed throughout German romanticism, expressing concerns and anxieties inseparable from his poetic and literary production.
\end{abstract}

Keywords: Tieck, Romanticism, Gothic, marvellous.

\section{Luzes e assombrações}

The curfew tolls the knell of parting day,

The lowing herd wind slowly o'er the lea

The plowman homeward plods his weary way,

And leaves the world to darkness and to me.

(Thomas Gray - Elegy Written in a Country Churchyard, 1751)

O século XVIII é tradicionalmente conhecido como época de racionalidade, pensamento lógico, avanços científicos e combate às superstições. Na literatura, estudiosos como Ian Watt 
e Richard Matthews localizam nessa época o surgimento de uma forma de romance que expulsa a dimensão mítica e arcaizante, substituindo-a por diversos elementos "realistas" tais como o protagonista caracterizado social e culturalmente; a descrição de aspectos provenientes da vida prática e cotidiana; o emprego de uma linguagem clara e objetiva; a escolha de temas ligados à exploração e conhecimento do mundo, etc. A literatura, assim, afasta-se cada vez mais dos ideais estéticos amparados nos valores aristocráticos e torna-se, em ritmo progressivo, porta-voz de uma classe média urbana que busca, na ciência e nas artes, instrumentos a serviço de sua ascensão econômica e social.

Contudo, o século XVIII não presenciou apenas o cientificismo. Paradoxalmente ele também viu a proliferação de formas de expressão poética e artística talhadas pelas sombras da noite, pelas condições mórbidas, pelos meandros assustadores do sobrenatural. Da pintura espectral de um Henry Fuseli (The Nightmare, 1781) à poesia taciturna da Graveyard School (ver BOTTING, 1996, p.32-38) - para a qual contribuiram Thomas Gray, Robert Blair, William Collins, James MacPherson, Thomas Percy, Edward Young, etc. -, artistas e público buscaram não o clarão das "luzes", mas a obscuridade e o mistério tanto do além (sobrenatural) quanto da própria realidade (natural).

Racionalidade e irracionalidade caminharam, assim, lado a lado no século XVIII e pelo século XIX adentro. Nesse sentido, vale a pena lembrar da famosa frase de Friedrich Laun e Johann Apel "Justamente quando desaparecem os fantasmas é chegada a época de sua história"1 (apud WEBER, 1981, p. 136 - tradução nossa) - que abre o livro Gespensterbuch [Livro de fantasmas], uma das primeiras antologias alemãs de histórias de fantasmas (1810). A frase dos dois editores remete à tensão entre o avanço dos conhecimentos "ilustrados" e o pressentimento de que a ciência, por mais que investigue e 
esclareça, nunca poderá eliminar o mistério e a curiosidade por aquilo que não se deixa destrinchar pelo microscópio. As páginas da literatura são, por conseguinte, o espaço onde o mundo - percebido ou apenas intuído - sempre permite a liberação da sensibilidade, a interpretação subjetiva, o assombro e $\mathrm{o}$ arrepio.

Trata-se, assim, de um veio literário contraposto ao espírito das Luzes, mas que, não obstante, se ampara em mecanismos nitidamente absorvidos do Racionalismo da época. Nesse sentido, com base em Dietrich Weber (1981, p. 136-137), é possível mencionar: abundância de informações destinadas a dar credibilidade factual à narrativa (ação passa-se em lugares verídicos, personagens são identificados como membros de famílias conhecidas e respeitadas); caráter investigativo (o encontro com a aparição sobrenatural é descrito passo a passo e em minúcias, como em uma pesquisa científica); argumentos em prol da verossimilhança (eventos são narrados como episódios vividos e lembrados) ${ }^{2}$. Leslie Fiedler (1990, p. 138) ainda acrescenta a busca por respeitabilidade mediante o estratagema de se apresentar elementos mágicos ou sobrenaturais como se fossem ciência. Nesse caso, inicialmente foram utilizadas a astrologia e alquimia, passando-se depois ao mesmerismo e finalmente à física moderna.

A literatura dedicada a temas e aspectos sinistros e sobrenaturais representa uma fenda na polida superfície da ilustração setecentista, deixando passar novas alternativas de manifestação literária. Entre essas manifestações, o romance gótico é a que desfrutou de maior popularidade e causou impacto mais profundo e duradouro, continuando a proliferar muito além de sua "época áurea" e possuindo descendentes diretos e indiretos nas histórias macabras - de autores como Wilkie Collins, Ambrose Bierce, H. P. Lovecraft, Stephen King -, nos romances policiais e nos muitos influxos 
que propiciou a gêneros vizinhos, como os contos fantásticos e as narrativas maravilhosas, tais como as escritas por Ludwig Tieck.

Uma pequena incursão pela obra de Tieck permite trazer à tona aspectos menos divulgados envolvendo a repercussão do gótico na Alemanha.

\section{Ludwig Tieck}

Ludwig Tieck (1773-1853) foi um dos pioneiros do Romantismo alemão e uma das figuras mais conhecidas e lidas de seu tempo. Seus textos, além de reverberarem na Alemanha, tiveram forte impacto na Grã-Bretanha (Thomas Carlyle), Espanha (Gustavo Adolfo Bécquer), Estados Unidos (Nathaniel Hawthorne), onde foram traduzidos e discutidas. Relegado após a morte ao esquecimento, Tieck teve sua obra revalorizada somente a partir de meados do século XX. Hoje está sendo recuperado como um dos expoentes da literatura romântica que associa elementos do maravilhoso a traços góticos (corrente denominada de Schauerromantik) na Alemanha.

Tieck foi, entre os românticos do Círculo de Jena, certamente aquele com produção ficcional mais extensa, tendo criado contos de fadas (ou Kunstmärchen ${ }^{3}$ ), romances, peças de teatro, novelas históricas, narrativas com temática social, etc. Também sobressaiu como tradutor de Cervantes (1799-1801) e Shakespeare ${ }^{4}$ (18251833), e como editor, sendo responsável por lançar em 1802 as obras de Novalis (falecido no ano anterior) e em 1821 a produção de Heinrich von Kleist (que se suicidara em 1811). A amizade com Samuel Coleridge e sua grande admiração por Calderón de la Barca e Shakespeare atestam a postura cosmopolita de Tieck e sua concepção da literatura como matéria que desconhece fronteiras nacionais ou de qualquer tipo (ver THALMANN, 1978, p. 871-872). 
Em meio a sua produção de viés gótico, destacam-se contos como "Der blonde Eckbert" ["O loiro Eckbert"] de 1797, "Der Runenberg" ["A montanha das runas"] de 1804, "Liebeszauber" ["Feitiço de amor"] e "Der Pokal" ["O cálice"] de 1811, que mais tarde foram enfeixados no volume Phantasus (1812). Nesses textos, é característico o entrelaçamento de traços abstraídos do gênero maravilhoso com elementos sinistros e grotescos: corações inocentes e singelos deparam-se ou cometem bruxarias, pactos macabros e crimes hediondos, os quais colocam o protagonista em situações-limite e muitas vezes lhe custam o entendimento e a vida. Tieck ampara-se aqui na lição de seus precursores, entre os quais se listam tanto os romances góticos da segunda metade do século XVIII, a exemplo de The Monk [O monge] (1796), de Matthew G. Lewis, quanto algumas baladas alemãs da mesma época, como "Lenore" ["Leonor"] (1773) ou "Der wilde Jäger" [“O caçador selvagem”] (1774), de Gottfried August Bürger, cujos protagonistas acabam enredados por forças sinistras e se perdendo nos labirintos de tramas diabólicas.

De seus antecessores góticos Tieck absorve os temas sinistros, as paisagens ermas e soturnas, as inexoráveis guinadas de fortuna. Por sua vez, ele faz uso desses elementos, impregnando-os do desassossego próprio do Romantismo alemão, que sempre buscou o desconhecido e misterioso, o longínquo e inalcançável, o inaudito e surpreendente. O sobrenatural escabroso serve a Tieck para produzir um efeito desestabilizador, buscando abalar as certezas de um leitor que se sente seguro e confortável em sua crença na Razão como resposta última para todas as questões. Em Tieck a incógnita não se deixa esgotar porque a própria realidade é entendida pelo autor como múltipla e variável.

Com ousadia e poder de inovação, os contos de Tieck abrem caminho a autores que, ainda durante o Romantismo, se embrenharam 
pelas brumas do desconhecido, conforme exemplificam obras de Joseph von Eichendorff ("Die Zauberei im Herbste" ["Sortilégio de outono" 5] de 1808-9), Achim von Arnim ("Melück Maria Blainville" de 1812), E. T. A. Hoffmann ("Der Sandmann" ["O homem da areia"] de 1819), entre outros.

A leitura de "O loiro Eckbert", conto mais divulgado e lido de Ludwig Tieck, pode nos dar uma amostra das estranhas paisagens poéticas criadas pelo seu autor.

\section{“O loiro Eckbert"}

"[...] sair do bom caminho nunca traz bons frutos, o castigo é infalível e nunca é tarde demais para ele." (TIECK, 2009, p. 35)

O conto "O loiro Eckbert" está, segundo Achim Hölter (2005, p.69-71), entre os textos da literatura alemã que mais vezes foram analisados e comentados, tendo sido submetido ao escrutínio das mais variadas correntes teóricas. Paradoxalmente, as primeiras linhas da narrativa delineiam uma situação de banalidade, introduzindo aos olhos do leitor o cotidiano da vida simples, ordeira e reclusa de um casal de meia idade - Eckbert e Bertha —, que, aparentemente, nada tem de complexo ou extraordinário. $\mathrm{O}$ caráter pacato desse ponto de partida potencializa o contraste frente aos eventos seguintes, que comprometem tanto Bertha quanto Eckbert em mentiras, traições, atos de impiedade e violências, instituindo como fio condutor do conto o tema da culpa.

De um lado, guardadas as devidas proporções - já que se trata de conto com vinte e poucas páginas -, podemos ver nesse conjunto de transgressões (que chegam a incluir assassinato e incesto) crimes e aberrações do mesmo quilate daqueles que pululam nas páginas 
de Matthew Lewis. Por outro, é possível reconhecer na construção ficcional que Tieck erige sobre o tripé crime/inocência, justiça/castigo e remorso/penitência as vigas que mais tarde darão sustento a produções como Michael Kohlhaas e A marquesa de O... (Kleist), O processo e $O$ veredito (Kafka), O casamento do Sr. Mississippi e A pane (Dürrenmatt).

"O loiro Eckbert" divide-se claramente em duas partes: na primeira, Bertha relata a história de sua infância, quando fugiu da casa dos pais e chegou a uma cabana solitária, encontrando abrigo junto a uma velha senhora e seus animais encantados, os quais ela rouba e mata para apropriar-se de riquezas; na segunda, Eckbert assassina seu antigo amigo Walther, que considera culpado pela morte repentina de Bertha, e conhece Hugo, mas também se sente ameaçado por ele, acabando por convencer-se ao final de que Hugo, Walther e a Velha da cabana são a mesma pessoa. Chegando depois de tumultuada jornada à mesma floresta da infância de Bertha, Eckbert ainda descobre que ela era sua irmã e sucumbe aos pés da Velha, esmagado pelo peso da solidão que marcou sua vida.

As duas etapas que compõem o texto configuram-se como deslocamentos, sendo os viajantes ora Bertha, ora Eckbert. Nos dois casos, o trajeto parte de um mundo conhecido (aldeia de Bertha, castelo de Eckbert) e termina na "solidão da floresta" ("Waldeinsamkeit") onde vivem a Velha, seu cachorro e o pássaro mágico. A semelhança entre os nomes dos personagens centrais não é gratuita, apontando para o papel complementar dos dois no texto. Somando-se as suas trajetórias, temos infância (Bertha) e vida adulta (Eckbert); partida da floresta e retorno; roubo e restituição; sentimento de culpa e expiação.

Para Winfried Freund (1999, p. 132-133), trata-se de característica tipicamente romântica o fato de descobrirmos o mistério e sordidez justamente onde menos se esperaria. Em outras palavras: o romântico 
busca revelar o "anormal" dentro da própria "normalidade" prosaica do dia-a-dia. $\mathrm{O}$ mágico e horripilante não fazem parte de outro mundo, mas daquele que conhecemos cotidianamente. A percepção, porém, daquilo que se esconde sob a superfície requer um olhar mais aguçado - e, para estimular essa qualidade de observação, o texto faz um uso estratégico da descrição.

Assim, o primeiro momento em que a situação imóvel e tranquila (na qual viviam os dois protagonistas antes da revelação de Bertha sobre seu passado fabuloso na cabana da floresta) se transforma em condição de angústia e esfacelamento (que primeiro aniquila Bertha e depois arrasta Eckbert para a perdição) é sinalizado no texto pela descrição do ambiente. Em outras palavras, a ambientação inóspita avisa ao leitor que um futuro desastroso se aproxima: "a noite espreitava lúgubre pelas janelas adentro, e as árvores no lado de fora estremeciam com a fria umidade" (TIECK, 2009, p.24). A descrição do espaço ganha, com isso, o papel de antecipar a reviravolta nefasta. Desse modo, a paisagem deixa de ser um pano de fundo para tornarse uma instância de representação da trama.

Outro exemplo desse poder de significação do espaço dá-se dentro da história narrada por Bertha, quando ela abandona a aldeia dos pais e, para chegar à mágica cabana da Velha, precisa enfrentar os horrores de um mar de rochedos, que quase lhe custou a vida.

Os rochedos à minha volta começaram nesse ponto a apresentar uma forma diferente, bem mais estranha. Eram penhascos empilhados uns sobre os outros, que davam a impressão de que o primeiro sopro de vento os faria despencar para todos os lados. [...] os rochedos foram tornando-se cada vez mais tenebrosos, obrigando-me diversas vezes a passar bem próximo a abismos vertiginosos, e, por fim, até mesmo a trilha sob os meus pés desapareceu. Fiquei absolutamente desconsolada, chorei e gritei, 
e o eco de minha voz respondeu nos vales rochosos de uma maneira aterrorizante [...]. À minha frente havia um rochedo íngreme; [...] quando alcancei o cimo, tudo ao meu redor, tão longe quanto a vista alcançava, era igual ao lugar em que me encontrava, tudo estava submerso em uma neblina perfumada, o dia estava cinzento e lúgubre, e meus olhos não conseguiam distinguir nenhuma árvore, nenhum prado, nenhum arbusto sequer, exceto umas poucas ramas dispersas que haviam crescido, solitárias e tristonhas, de algumas fendas estreitas nas rochas. (TIECK, 2009, p.28-29)

Bertha, antes de iniciar sua narrativa, havia avisado a seus ouvintes (Eckbert e Walther) que sua história poderia vir a soarlhes como "um conto de fadas" (2009, p.25). Tal aviso metaficcional já prepara o leitor para a iminência de eventos incomuns. Longe de caminhar para o maravilhoso, porém, o texto nos conduz para uma “natureza demoníaca” (KLOTZ, 1985, p. 154): conforme a descrição do lugar vai revelando sua monstruosidade, a árida paisagem de rochedos torna-se cada vez mais semelhante a uma assombração gótica tornada surreal pela sua inexplicável imensidão. Atravessála equivale a transpor uma muralha destinada a afugentar eventuais visitantes da cabana na floresta, onde Bertha viverá por anos a fio como em um paraíso: sem os sofrimentos que conheceu na aldeia natal (típicos dos mortais) e sem jamais ver chegar ali outra pessoa além dela mesma.

Os rochedos desabitados foram ficando cada vez mais para trás, atravessamos uma suave campina e depois um bosque bastante extenso. Quando chegamos ao fim dele o sol estava justamente se pondo, e jamais me esquecerei da imagem e da sensação desse entardecer. Tudo se fundia em delicados tons rubros e dourados, as árvores erguiam suas copas no arrebol, e pelos campos derramava-se um clarão encantador; as matas e 
as folhas das árvores estavam imóveis, o céu límpido parecia um paraíso de portas abertas, e o murmúrio das fontes e o ocasional zunir das árvores atravessavam aquela risonha calmaria com um tom de jubilosa melancolia. Minha alma juvenil alcançou então, pela primeira vez, uma ideia do que era o mundo e suas particularidades. Esqueci-me de mim e de minha guia, meu espírito e meus olhos apenas voavam entusiasmados por entre as nuvens douradas. (TIECK, 2009, 30-31)

Embora a própria personagem cresça, passando de criança para adulta, nada em sua volta se altera: em vez do ciclo de estações (mobilidade da natureza), cada dia é igual ao anterior (imobilidade mítica). Assim, a "solidão do bosque" ("Waldeinsamkeit") — à qual o pássaro mágico se refere em sua canção ${ }^{8}$ e que perpassa toda a narrativa como um incansável refrão - não equivale ao mundo "natural", e sim a uma esfera transcendente ou mágica. A recôndita cabana que Bertha encontra em sua infância nos remete à Idade de Ouro descrita por Hesíodo - tempo utópico de plenitude, espiritualidade e felicidade, que se tornou objeto da nostalgia romântica. Birrell (1979, p. 51), porém, defende que Tieck não nos mostrou um retrato da Idade de Ouro em toda a sua perfeição, mas moldado conforme os olhos e a capacidade de compreensão de uma criança nas condições de Bertha. O que Bertha encontra junto à Velha não é inefável grandiosidade, mas uma tranquila felicidade doméstica - que ainda ganha um espírito bem ao gosto de Rousseau:

[...] minha pequena roca chiava, o cão latia, o pássaro mágico cantava enquanto a região na circunvizinhança se mantinha tão serena que não me recordo de ter havido durante todo esse tempo qualquer vendaval, qualquer tempestade. Nunca ninguém perdeu o caminho e foi dar ali, nenhum animal selvagem aproximava-se de nossa morada, eu estava satisfeita e cantava, e meu trabalho fazia os dias se sucederem [...]. O ser 
humano talvez fosse bastante feliz se lhe fosse possível manter até o fim uma vida tão tranquila. (TIECK, 2009, p. 34)

A queda, porém, já é previsível, e Bertha cede à tentação das ambições mundanas. Assim como a Velha reúne traços tanto bondosos quanto horripilantes, o bosque de bétulas é paraíso assim como inferno. Para Achim Hölter (2005, p. 76-77), trata-se de um espaço localizado em uma esfera própria, em que a Velha é o poder supremo de decisão dos destinos, assim como instrumento de execução de suas sentenças. Essas reverberações míticas entrelaçamse no texto de Tieck a elementos do maravilhoso.

A narrativa de Bertha apresenta assim diversos pontos de intersecção com contos de fadas: a Velha em sua casinha na floresta tem aspectos em comum com a bruxa de "João e Maria" (Grimm); a menina que sofre maus tratos em casa e sobrevive à jornada para um lugar distante e fabuloso, encontrando ali abrigo e serenidade, tem equivalente em "A senhora Holle" (Grimm); a sequência de fuga e, anos mais tarde, represália também está no enredo de "Branca de Neve" e "Irmãozinho e Irmãzinha" (ambos de Grimm); o roubo de um pássaro que diariamente bota ovos contendo pedras preciosas faz lembrar da galinha dos ovos de ouro, subtraída ao ogro pelo protagonista de "Jack e o pé de feijão" (J. Jacobs). Em todos esses casos, a intersecção se dá com contos de fadas dotados de aspectos terríveis, que vão do canibalismo a assassinato e outras formas de violência. No entanto, se nesses contos de fadas mencionados os heróis superam as forças maléficas, Eckbert é engolido pelo turbilhão de revelações escabrosas com que a Velha o confronta. Em Tieck, a bruxa é a vencedora. Mais do que isso: ela surge como uma instância ineludível que, qual uma moira do destino, controla as etapas do fio da vida e, por fim, corta-o. 
Para Klotz (1985, p. 160), a "tenebrosa fatalidade" corporificada pela Velha confere ao conto um caráter trágico e atemporal: Bertha e Eckbert são "culpados inocentes" que, tal como Édipo, cometem delitos porque estavam destinados a cometê-los. Já Pikulik (1979, p. 176-177) relaciona a culpa dos dois à do Gênesis. Como Bertha apenas começa a ansiar por riquezas e uma vida mundana após ler os livros que encontrou na cabana da Velha, o comentador considera que tais leituras equivalem ao contato com a árvore do conhecimento, de modo que a transgressão de Bertha e seu desligamento da cabana na floresta corresponderiam à expulsão do Éden.

Seja como for, perdão e segunda chance estão excluídos. Qual joguetes na mão de forças demoníacas, os dois protagonistas trilham seu caminho de perdição, que desemboca na loucura de Eckbert. Desconectado de todos os laços, assim como de todos os referenciais de sentido para sua existência, Eckbert - que perdeu a esposa, assassinou o melhor amigo, e foi traído por Hugo - perde noção de si e do que o rodeia. Todos que cruzam seu caminho parecem mesclar-se, reduzindo-se a uma única pessoa:

[...] Finalmente encontrou um velho camponês que lhe indicou um caminho que passava por uma cachoeira; quis dar-lhe algumas moedas em agradecimento, mas o camponês as recusou. - Que importa? - disse Eckbert consigo - eu poderia acabar imaginando outra vez que ele é Walther!

E nisso volveu os olhos novamente para trás e era Walther! [...] Isto deu um golpe fatal na mente, no juízo de Eckbert; ele não conseguia encontrar a chave do enigma: estaria sonhando agora ou teria ele sonhado outrora com uma mulher chamada Bertha; as coisas mais fantásticas mesclavam-se às mais banais, o mundo ao seu redor estava enfeitiçado, e ele não era capaz de qualquer pensamento, qualquer recordação. (TIECK, 2009, p. 47-48) 
A realidade de Eckbert - já restrita a um círculo diminuto (estando de início praticamente circunscrita ao espaço do castelo e ao convívio com Bertha e Walther) - encolhe ainda mais, convergindo para um único ponto: a Velha na cabana da floresta. $\mathrm{O}$ efeito desse redemoinho para o leitor é de choque e horror, pois a percepção de Eckbert se esfacela a ponto de ele não mais distinguir os outros entre si, e os outros dele mesmo. Conforme apontado por Leopoldseder, duas condições se realizam aqui: a cisão do eu (que perde sua integridade e se confunde com o não-eu) e a dilaceração da causalidade (acompanhada da manifestação do absurdo). Para Leopoldseder, fica evidente que em "O loiro Eckbert" e outros contos de Tieck "poderes tenebrosos puxam os personagens para o abismo. A incapacidade de compreender racionalmente essas forças conduz os personagens à loucura, na qual todas as categorias são canceladas." (1973, p.101-102 - tradução nossa).

Segundo Marianne Thalmann, os contos maravilhosos (ou Kunstmärchen) de Tieck levantam questões típicas da modernidade: "Existe apenas uma única realidade? Somente uma verdade? Tem um enigma apenas uma solução?” (1978, p.875 - tradução nossa). A narrativa de Tieck desestabiliza as certezas em dois níveis: de um lado, o leitor nunca recebe do narrador uma confirmação sobre o que Eckbert presenciou e o que apenas imaginou; de outro, o leitor é confrontado com a ideia de que nenhuma realidade é inequívoca ou plenamente cognoscível. Tanto a realidade ficcional como a extraficcional são semelhantes a relevos contendo rachaduras, quinas e túneis que obliteram a visão, impedindo que o olhar alcance todos os pontos.

Nessa paisagem intrincada movimentam-se Eckbert e outros protagonistas de Tieck, figuras complexas e angustiadas por suas lembranças e intuições, e rasgadas por seus impulsos e sua consciência, 
digladiando-se com problemas existenciais que não conseguem entender, quanto mais solucionar. Trata-se de personagens expulsos do conforto da "normalidade" e predestinados a visitar esferas inalcançáveis à maioria. A representação ficcional desse estado de coisas é instrumentalizada pelo recurso ao sobrenatural.

Nos contos de Tieck, o sobrenatural - quer ele tenha mais carregadas as cintilações do maravilhoso, quer esteja mais mergulhado nas penumbras do gótico e horripilante - traduz metaforicamente a experiência de transpor um umbral e vislumbrar aquilo que se oculta por debaixo da superfície. O encontro com o sobrenatural é produzido pelo olhar que roça o desconhecido, misterioso e proibido, dando margem então ao efeito de estranhamento. Os protagonistas de Tieck - assim como depois os de E. T. A. Hoffmann - são indivíduos que se destacam por serem mais sensíveis e instáveis (do que a maioria), e menos adaptados às convenções de seu ambiente. Esses protagonistas transgridem as fronteiras - geográficas, assim como sociais - em busca do que está além de sua terra natal e que transcende o permitido.

Conforme já apontou Thalmann (1978, p.875), os contos de Tieck se iniciam em um dia inusitado ou estranho, no qual acabam ocorrendo eventos incomuns que acarretam a reviravolta. No caso de "O loiro Eckbert", trata-se do momento em que o protagonista pede a sua esposa que conte a história de sua infância ao amigo Walther, e, dentro dessa história, por sua vez, do dia em que Bertha foge da casa dos pais. Com essa narrativa da viagem de Bertha à cabana na floresta e dos anos em que viveu com a Velha, o pássaro mágico e o cachorrinho, Eckbert pretendia fortalecer os laços de amizade com Walther. A revelação do passado selaria a franqueza e confiança entre ambos. Ao contrário do esperado, Walther não é quem Eckbert acreditava ser. E, assim, a revelação traz de imediato a desconfiança 
em relação a Walther e, dentro de algumas horas, o desaparecimento irrevogável da vida que o casal levava em seu castelo.

O passado matou o presente, mas, antes, o presente asfixiava o passado, pois a narrativa dos eventos prodigiosos da infância evidenciou que havia uma falha da memória: Bertha recordava-se de inúmeros detalhes, menos o nome do cãozinho da Velha. Terminada a narrativa, Walther inesperadamente menciona o animal por seu nome (Stromian), revelando que já tinha conhecimentos prévios da história - com isso, o maravilhoso do passado transforma-se em uma perspectiva aterradora, que aniquila o presente e ameaça permanentemente o futuro. Bertha morre, pois percebe em Walther uma força demoníaca e vingativa que vem cobrar o preço pela antiga culpa (fuga de Bertha da cabana, roubo das jóias, morte dos dois animais mágicos). Eckbert, por sua vez, inicia uma peregrinação que o levará a afundar-se no crime e na loucura. $\mathrm{O}$ conto de fadas transformou-se em história de horrores.

O momento de encontro com o insólito rompe o alicerce social do indivíduo, lançando-o em isolamento: sua realidade não é mais compartilhada com seus antigos familiares ou amigos. O protagonista de Tieck é alguém que, em dado instante, percebe haver um mistério por sob a superfície das pessoas e coisas. Entrever essa região fabulosa, no entanto, pode custar caro a um reles mortal, assim como a ousadia de Ícaro também foi cobrada a um alto preço. Os protagonistas de Tieck, e do Romantismo alemão em geral, muitas vezes transpõem os limiares da vida regrada e segura (à qual se apegam os cidadãos comuns) e penetram em santuários sobre-humanos (reservados aos deuses, mas que são acessíveis aos gênios inspirados).

Essa experiência pode configurar-se como mágica viagem pelo maravilhoso ou ser vista como pesadelo infernal e aterrador. Em "O loiro Eckbert", assim como em outros contos, a exemplo de "A 
montanha das runas" ou "Feitiço de amor", uma delicada atmosfera de ingênuo encantamento alterna-se com os tempestuosos horrores de um mundo de trevas e perdição. No conto aqui analisado, Tieck comprova especial maestria em tecer a trama de fios díspares, produzindo uma narrativa de caráter enigmático e inusitado na época.

Escrevendo "O loiro Eckbert" em 1796 (publicado no ano seguinte), Tieck produziu um texto que, na Alemanha, constrói a passagem do gótico do século XVIII ao fantástico do século XIX (na acepção de Todorov). O comentário de Bertha, de que "uma estranha batalha travou-se em [sua] alma, como se houvesse [nela] dois espíritos rebeldes em combate" (2009, p. 37), carrega a faceta de dubiedade do fantástico, assim como o gérmen da cisão do homem moderno. A loucura que se apossa de Eckbert ao final do conto não é expediente ficcional simplório, mas metáfora do desenraizamento e perda de referenciais do indivíduo. Ela aponta para a falência da crença absoluta nas luzes do racionalismo como resposta às grandes questões do homem sobre o mundo e sobre sua própria humanidade. Eckbert, assim como os protagonistas de outros românticos - Heinrich von Ofterdingen (Novalis), Ondina (Fouqué), Peter Schlemihl (Chamisso), Anselmo (Hoffmann) -, seguiu uma trajetória de permanente busca. As perguntas levantadas não admitem resposta única.

Ludwig Tieck lançou mão de uma gama de recursos estéticos que solidificam sua obra no cenário literário. Assim como Mary Shelley na Inglaterra, Nathaniel Hawthorne nos Estados Unidos, Álvaro do Carvalhal em Portugal, Álvares de Azevedo no Brasil, etc., Tieck utilizou o gótico como instrumento poético inovador, capaz de fertilizar a expressão de linguagem artística. 


\section{Notes}

1. "Gerade wenn es mit den Gespenstern aus ist, geht das rechte Zeitalter für ihre Geschichte an".

2. Veja-se, a título de exemplo, o início do conto "Das Bettelweib von Locarno" ["A mendiga de Locarno"] (1810), de Heinrich von Kleist: "Ao pé dos Alpes, perto de Locarno, ao norte da Itália, encontra-se um velho castelo que pertencia a um marquês. Quem hoje vem de São Gotardo verá que do castelo só restam escombros e cinzas: um castelo com altos e espaçosos aposentos, num dos quais há muitos anos a dona da casa, movida pela compaixão, alojara sôbre palhas uma velha doente que mendigava à porta." (KLEIST, 1972, p.124).

3. Trata-se aqui de uma criação "literária” (não originária da tradição oral) e, portanto, distinta do conto de fadas popular (Volksmärchen).

4. Até os dias de hoje, a tradução das obras completas de Shakespeare, elaborada em conjunto por Tieck e August Schlegel, é considerada a melhor versão do dramaturgo inglês para o idioma alemão.

5. Em tradução brasileira no volume: CALVINO, Italo (Org.). Contos fantásticos do século XIX. Tradução de Rosa Freire D’Aguiar e outros. São Paulo: Companhia das Letras, 2004.

6. Em tradução brasileira no volume: MANGUEL, Alberto (Org.). Contos de horror do século XIX. Tradução de Rubem Fonseca e outros. São Paulo: Companhia das Letras, 2005.

7. Disponível em diversas traduções brasileiras.

8. Os versos "Doce solidão / Do bosque, que alegria / Dia após dia / E pelos tempos que virão / Oh, como me delicia / Doce solidão." são repetidos diversas vezes ao longo do conto, formando uma espécie de fio condutor e alçando a solidão da floresta de bétulas à condição de Leitmotiv da narrativa como um todo.

\section{Referências bibliográficas}

BIRRELL, Gordon. The Boundless Present: Space and Time in the Literary Fairy Tales of Novalis and Tieck. Chapel Hill: University of North Carolina, 1979. 
BOTTING, Fred. Gothic. London: Routledge, 1996.

FIEDLER, Leslie. The Substitution of Terror for Love. In: SAGE, Victor (Ed.). The Gothick Novel. Houndmills: The Maximilian Press, 1990. p. 130-139.

FREUND, Winfried. Deutsche Phantastik: Die phantastische deutschsprachige Literatur von Goethe bis zur Gegenwart. München: Wilhelm Fink Verlag, 1999.

HÖLTER, Achim. Über Weichen geschickt und im Kreis gejagt. Wie Tiecks "Blonder Eckbert" den modernen Leser kreiert. In: KREMER, Detlef (Ed.). Die Prosa Ludwig Tiecks. Bielefeld: Aisthesis, 2005. p. 69-94.

KLEIST, Heinrich von. A mendiga de Locarno. In: LANGENBUCHER, Wolfgang (Sel.). Antologia humanística alemã. Tradução de Ari Lazzari e outros. Porto Alegre: Ed. Globo, 1972. p. 124-126.

KLOTZ, Volker. Ludwig Tieck. In: Das europäische Kunstmärchen. Stuttgart: J. B. Metzler, 1985. p. 149-161.

LEOPOLDSEDER, Hannes. Groteske Welt: Ein Beitrag zur Entwicklungsgeschichte des Nachtstücks in der Romantik. Bonn: Bouvier Verlag, 1973.

LEWIS, Matthew Gregory. The Monk. London: New English Library, 1973. MATTHEWS, Richard. Fantasy: The Liberation of Imagination. London: Routledge, 2002.

PIKULIK, Lothar Romantik als Ungenügen an der Normalität. Frankfurt a.M.: Suhrkamp, 1979.

THALMANN, Marianne. Nachwort. In: TIECK, Ludwig. Die Märchen aus dem Phantasus / Dramen. München: Winkler Verlag, 1978. p. 871-888.

TIECK, Ludwig. Die Märchen aus dem Phantasus / Dramen. München: Winkler Verlag, 1978.

TIECK, Ludwig. Feitiço de amor e outros contos. Introdução de Maria Aparecida Barbosa. Tradução de Maria Aparecida Barbosa e Karin Volobuef. São Paulo: Hedra, 2009.

TODOROV, Tzvetan. Introdução à literatura fantástica. São Paulo: Ed. Perspectiva, 1975. 
172 Karin Volobuef, Ludwig Tieck: meandros góticos

WATT, Ian. The Rise of the Novel: Studies in Defoe, Richardson and Fielding. Berkeley: University of California Press, 1957.

WEBER, Dietrich. Gespenstergeschichte. In: KNÖRRICH, Otto (Ed.). Formen der Literatur in Einzeldarstellungen. Stuttgart: Alfred Kröner Verlag, 1981. p. 136-142.

WÜHRL, Paul-Wolfgang. Das deutsche Kunstmärchen: Geschichte, Botschaft und Erzählstrukturen. Heidelberg: Quelle \& Meyer, 1984.

[Recebido em 22/12/2011. Aprovado em 01/04/2012] 